\title{
Notas Sobre a Noção de Inconsciente em Wundt e Leibniz ${ }^{1}$
}

\author{
Hélio Honda ${ }^{2}$ \\ Universidade Estadual de Maringá
}

\begin{abstract}
RESUMO - O artigo inicia discutindo os equívocos da leitura dos psicólogos anglo-americanos, motivados pela perspectiva empirista a partir da qual tentaram compreender a psicologia de Wundt. Em seguida, discute a noção de inconsciente em Wundt e mostra sua vinculação com o racionalismo da filosofia de Leibniz. Defende que a compreensão de teorias e sistemas em psicologia impõe como necessidade a consideração de seus fundamentos epistemológicos e filosóficos.
\end{abstract}

Palavras-chave: inconsciente; Wundt; Leibniz.

\section{Notes on the Concept of Unconscious in Wundt and Leibniz}

\begin{abstract}
The article begins discussing the misunderstandings of the Anglo-American psychologists' reading, motivated by the empiricist perspective from which they tried to understand the Wundt's psychology. Soon after, explicit the concept of unconscious in Wundt, and it shows its relationship with the rationalism of Leibniz's philosophy. It defends that the understanding of theories and systems in psychology imposes the need of considering of their epistemological and philosophical foundations.
\end{abstract}

Key words: unconscious; Wundt; Leibniz.

Desde o veto de Comte às pretensões de cientificidade por parte da Psicologia, esta buscou incessantemente renovar-se conceitual e metodologicamente, de modo que viesse a tornar-se merecedora desse estatuto (Gréco, 1967). A história oficial nos mostra que a tentativa mais radical nesse sentido encontra-se no desenvolvimento da chamada "psicologia experimental," ${ }^{3}$ a partir do estabelecimento, por Wilhelm Wundt (1832-1920), do primeiro laboratório de psicologia em Leipzig, no ano de 1879.

Uma das mais relevantes investigações desenvolvidas no domínio da história e da epistemologia da psicologia nas últimas décadas refere-se precisamente à reavaliação, tanto metodológica como filosófica, da obra de Wundt (Blumenthal, 1980; Danzinger, 1980; Leahey, 1979). Os resultados obtidos nesses estudos demonstraram o equívoco daqueles considerados herdeiros de seu ideário, a saber, o psicólogo Edward Bradford Titchener (1867-1927) e seus seguidores. Veremos mais adiante que esse equívoco resulta da não compreensão do pensamento de Wundt, em particular a não compreensão dos limites estabelecidos pelo psicólogo alemão ao método experimental no estudo dos processos mentais. Por esta razão, o projeto da psicologia experimental americana, supostamente baseado no modelo concebido por Wundt, viu-se, desde o seu início, comprometido em seus fundamentos.

1 O autor agradece o apoio financeiro da Capes e ao Prof. Dr. José Antonio Damásio Abib pelas sugestões durante o curso sobre História da Psicologia do Programa de Filosofia e Metodologia das Ciências da Universidade Federal de São Carlos.

2 Endereço: Universidade Estadual de Maringá, Av. Colombo, 5790 Maringá, PR, Brasil 87020-900.E-mail: hhonda@uem.br

3 Fazemos uso da expressão entre aspas, pois, veremos a seguir o quanto é equivocada, pelo menos da perspectiva de Wundt, a expressão psicologia experimental enquanto designação de um domínio de investigação próprio.
Problemas na compreensão do pensamento wundtiano não resultariam da dificuldade interna às concepções de Wundt, mas sim, da divergência entre as tradições filosóficas nas quais estavam inscritos, Wundt, por um lado, e os psicólogos americanos e ingleses, por outro. Enquanto a filosofia inglesa se encontra na tradição do empirismo, decorrente em especial de Locke, na filosofia alemã deparamo-nos com uma tradição racionalista, proveniente, principalmente, de Leibniz. ${ }^{4}$ Em decorrência de tal divergência na fundamentação filosófica, verificar-se-ia, no plano da psicologia, conseqüências que foram determinantes não apenas para os equívocos na compreensão do pensamento de Wundt, mas também para a constituição daquilo que seria o objeto próprio da psicologia para cada uma dessas vertentes. Em outras palavras, a tradição filosófica na qual os psicólogos se inserem tende a determinar a concepção do objeto de estudo e o método com o qual a ele se dirigem.

Grosso modo, para os psicólogos de tradição empirista, para quem os conteúdos mentais têm origem na experiência, pode-se admitir uma equivalência entre mente e consciência, de tal modo que através apenas do estudo desta última seria possível chegar a compreender aquela. Em outras palavras, a compreensão da mente humana poderia ser levada a cabo através do estudo dos fenômenos conscientes.

Wundt, por outro lado, inseria-se numa outra tradição, representada pelo racionalismo leibniziano. Leibniz, para além de Descartes, ${ }^{5}$ não levava em conta apenas as percepções claras e distintas, mas também as percepções obscuras

4 Exposição esclarecedora acerca da divergência entre essas duas tradições filosóficas pode ser lida em Blumenthal (1980) e Danzinger (1980).

5 Em Meditações, na busca de uma verdade absoluta para fundamentar o conhecimento, Descartes (1641/1973) utiliza como um dos critérios nessa empresa o da clareza e distinção. Por isso, considera como verdadeiras apenas as percepções claras e distintas, renegando as percepções obscuras e confusas ao domínio do erro e da falsidade. 
ou menores, as petites perceptions, que escapavam à consciência. Para esta tradição, portanto, a mente não poderia equivaler à consciência apenas; ao contrário, no domínio do mental, encontrar-se-iam conteúdos de diferentes graus, desde os mais claramente conscientes até os mais obscuros e inconscientes.

Baseado em tais pressupostos, na psicologia wundtiana, o estudo da consciência consistia no meio a partir do qual eram efetuadas inferências visando compreender a natureza da mente (Blumenthal, 1980; Danzinger, 1980). Para além dos fenômenos conscientes, no entanto, a psicologia de Wundt, que se constituía no estudo da mente e não apenas no da consciência, requeria, portanto, além da pesquisa dos processos conscientes, a investigação de processos não conscientes. Estes últimos, que poderiam ser considerados inconscientes, deveriam ser investigados por uma psicologia social, que, a partir do estudo dos fenômenos tidos como seus produtos ou manifestações, como a linguagem, o mito, a arte etc., também efetuaria suas inferências visando compreender a natureza desses processos inconscientes. ${ }^{6} \mathrm{O}$ método experimental, por outro lado, estaria limitado à investigação de processos mentais mais simples, como a atenção, a percepção, dentre outros.

Tornado vulgarmente conhecido pelos manuais de psicologia como o pai da psicologia experimental, por ter sido responsável pela instalação do primeiro laboratório de psicologia, para Wundt, no entanto, a investigação psicológica não se restringe ao laboratório, a uma psicologia experimental. Dada a amplitude dos fenômenos com os quais se ocupa, a psicologia, concebida por ele, requer dois métodos de investigação, a saber, um de caráter experimental e um outro de caráter social.

Uma das lições que podemos extrair da consideração dos resultados dos trabalhos de reavaliação do pensamento de Wundt é a clara necessidade de nos informar acerca dos fundamentos filosóficos subjacentes à psicologia que desejamos compreender. Nesse sentido, a não equivalência entre mente e consciência, característica da filosofia de Leibniz e do idealismo e romantismo alemães, constitui uma das fontes a partir da qual se desenvolve, no domínio da psicologia, a noção de inconsciente, tanto a concepção wundtiana como, talvez, também a sua expressão mais radical na crença freudiana e a sistematização conceitual em termos de um Sistema Inconsciente. Seguir esta trilha exigiria, porém, uma investigação cuja envergadura ultrapassa o escopo do presente trabalho. Nas notas que se seguem, limitamo-nos apenas a indicar alguns aspectos da noção de inconsciente que aparecem em An Introduction to Psychology de Wundt e sua relação com a filosofia de Leibniz.

\section{I}

É a partir dos experimentos realizados por Wundt (1911/1973), em especial o experimento com o taquitoscópio que podemos verificar o aparecimento da idéia de processos

6 Dado que este trabalho limita-se apenas a indicar alguns pontos pertinentes a uma comparação conceitual, não discutimos a concepção de psicologia social de Wundt. Além disso, uma tarefa dessa monta requereria, necessariamente, uma incursão pelos textos de sua Völkerpsychologie. mentais não conscientes. Grosso modo, esse experimento consistia na apresentação a um observador de uma folha ou placa contendo um conjunto de letras, solicitando-lhe que dirigisse sua atenção a uma determinada letra, localizada no centro desse conjunto. A exposição era efetuada em frações de segundo, após a qual solicitava-se ao observador que relatasse o maior número possível de letras que pudesse lembrar, localizadas ao redor do ponto de fixação. Segundo Wundt, a quantidade de letras reconhecidas como claramente conscientes chegava a três ou quatro. Na consideração dos seus resultados Wundt chegou a uma figuração do que seria o campo subjetivo: "uma região circundando um ponto de fixação, que se torna gradualmente mais obscura na direção da periferia (...)" (1911/1973, p. 15).

O campo subjetivo é representado, assim, como uma área no interior da qual estariam presentes conteúdos com graus variados de claridade ou nitidez, de modo que os mais claros e distintos encontrar-se-iam no entorno de um ponto de fixação. Estes conteúdos, presentes no que Wundt chamou "foco de atenção", comporiam uma espécie de "consciência clara", enquanto que aqueles que circundam tal foco, e se distribuem indistintamente até a periferia do campo subjetivo, formariam uma "consciência obscura".

Do ponto de vista funcional, Wundt chamou de "apreensão" àquela simples percepção de modo obscuro. Ou seja, a função apreensiva seria a responsável pelo acesso daquelas percepções que se distribuiriam pelo campo subjetivo mais amplo, o da consciência obscura. Entre as percepções claras, no entanto, uma outra função estaria presente, uma atividade denominada "apercepção". Seria também através da atividade aperceptiva que elementos presentes no campo da consciência obscura poderiam ser elevados, por meio da atenção, ao campo da consciência clara ou foco de atenção. ${ }^{7}$

Wundt dedica-se longamente à análise do mecanismo em jogo no processo aperceptivo, revelando na atividade de tornar consciente conteúdos antes inconscientes um caráter dinâmico e plástico. Por exemplo, se este processo for direcionado a um elemento isolado, "o resto, os elementos apenas psiquicamente apreendidos, desaparecem como se eles fossem não existentes" (1911/1973, p. 36). De tudo isso, o que nos interessa ressaltar aqui é o aspecto topológico da figuração de Wundt, no qual se sobressai uma espécie de palco sobre o qual se estendem os conteúdos psíquicos. Área subjetiva esta que, pela sua amplitude, não seria passível de ser num só tempo inteiramente abarcada pela atividade aperceptiva, assinalando continuamente a sombra da inconsciência.

\section{II}

Seguindo as trilhas do racionalismo cartesiano, mas divergindo deste em inúmeros aspectos, Gottfried Wilhelm Leibniz (1646-1716) retoma a distinção feita por Descartes entre as idéias claras e distintas, por um lado, e as idéias obscuras e confusas, por outro, passando a dar ênfase ao aspecto no

7 Cumpre observar aqui um aspecto de fundamental importância na psicologia de Wundt, a saber, o caráter ativo, volitivo, do processo psíquico denominado apercepção; atividade esta que não seria outra senão aquela já defendida por Locke, em Ensaio sobre o Entendimento Humano, como sendo peculiar à reflexão e assimilada por Leibniz em seus Novos Ensaios sobre o Entendimento Humano. 
qual, segundo ele, “falharam os cartesianos, ao desprezarem as percepções inapercebidas" (Leibniz, 1714/1979, p. 106). Para Leibniz, a percepção é o estado passageiro em que "o espírito é em geral puramente passivo, não podendo deixar de perceber o que percebe atualmente" (1765/1980, p. 84). Ao contrário, o pensamento "significa muitas vezes a operação do espírito sobre as suas próprias idéias, quando age e considera uma coisa com um certo grau de atenção voluntária" (p. 84). Desse modo, assim como os animais que possuem percepção sem que tenham necessariamente pensamentos, também nós possuímos aquilo que chama de "pequenas percepções", isto é, percepções das quais não temos consciência. Segundo Leibniz, percepções dessa natureza existem a todo o momento, porém sem "apercepção" ou percepção consciente através da reflexão. A subtração dessas percepções menores ao processo aperceptivo decorreria de sua insignificância e, apesar de serem em grande número, somente quando unidas poderiam se fazer sentir, mas, mesmo nesse caso, apenas de maneira confusa. A concepção leibniziana supõe uma continuidade entre a série perceptiva, de modo que se passaria, gradualmente, das menores às percepções maiores ou mais fortes e vice-versa. Assim, o que determinaria a apercepção de um dado conteúdo seria a sua força ou poder em atrair a nossa atenção.

Por outro lado, Leibniz considera que as pequenas percepções são infinitamente maiores em quantidade e muito mais eficazes em seus efeitos do que se imagina. Em um dos diversos momentos em que enfatiza essa peculiaridade das pequenas percepções, escreve que "jamais romperíamos uma corda com a maior força do mundo, se ela não começasse a ser esticada um pouco por esforços iniciais menores, ainda que esta primeira pequena distensão da corda não apareça" (1765/1980, p. 12). As pequenas percepções seriam, portanto, necessárias e, de certo modo, a condição para a apercepção. É nesse sentido que Leibniz, em A Monadologia, considera que uma substância encerrada em confusão, resultante de um grande número de pequenas percepções, quando despertada do aturdimento no qual se encontrava se apercebe dessas percepções; neste caso, escreve, "é absolutamente necessário havê-las tido imediatamente antes, embora inapercebidas na ocasião, pois uma percepção não proviria naturalmente a não ser de outra percepção (...)" (1714/1979, p. 107).

\section{III}

Já a partir dessas notas elementares, a homologia entre Wundt a Leibniz parece evidente, sobretudo, quando se recorda a concepção de Wundt acerca do processo de apercepção em sua relação com a mera apreensão. Ou seja, também para Wundt, a apercepção requer a presença de percepções antes apenas apreendidas, presentes na obscuridade do campo subjetivo como inconscientes. Em outros termos, o acesso de qualquer elemento perceptivo à consciência, para ambos os autores, dependeria de um processo que supõe, de antemão, o registro de tal elemento num estado anterior de inconsciência. Daí poder dizer que, para ambos, o domínio do mental, ou, na linguagem que nos interessa, o campo do psicológico, não pode ser limitado ao domínio da consciência - do campo da consciência clara, para Wundt. Ao contrário, o campo do psicológico supõe a consideração de uma vasta área habitada por conteúdos inconscientes.
Apesar da relação estreita entre as concepções de Wundt e as de Leibniz, é necessário ressalvar que correspondem a discursos de natureza distinta, ou seja, enquanto as concepções leibnizianas são de caráter filosófico e metafísico, as wundtianas são de caráter psicológico e empírico. Wundt chama a atenção para a diferença entre a sua preocupação e a de Leibniz no momento em que torna explícita sua filiação. Leiamos suas palavras:

Vamos usar duas curtas expressões para os dois processos, o de acesso à consciência e o de elevação ao foco de atenção - duas expressões [apreensão e apercepção] que foram introduzidas pela primeira vez por Leibniz em um sentido parecido (...). Não levaremos em consideração o sentido filosófico em que Leibniz usa essas expressões em sua teoria das mônadas. Nós usaremos essas expressões em seu sentido puramente empírico e psicológico (1911/1973, p. 35).

A relação entre Wundt e Leibniz e o uso que o primeiro faz de concepções do segundo, ainda que considerada aqui apenas pontualmente, aponta para uma relação estreita entre ciência e filosofia, no caso entre a psicologia wundtiana e a filosofia leibniziana que a informa. A despeito da temática em questão, era, antes de tudo, precisamente este tipo de vinculação que queríamos pôr em relevo com estas notas. Vinculação que impõe como condição para bem compreender teorias e sistemas em psicologia, a informação acerca de seus pressupostos epistemológicos e da tradição filosófica na qual se inserem não apenas seus mentores, mas também seus intérpretes.

\section{Referências}

Blumenthal, A. L. (1980). Wilhelm Wundt and early american psychology: A clash of cultures. Em R. W. Rieber \& K. Salzinger (Orgs.), Psychology: Theoretical-historical perspectives (pp. 25-42). New York: Academic Press.

Danzinger, K. (1980). The history of introspection reconsidered. Journal of the History of the Behavioral Sciences, 16, 241262.

Descartes, R. (1973). Meditações. (J. Guinsburg \& B. Prado Júnior, Trad.) São Paulo: Abril Cultural (Originalmente publicado em 1641).

Gréco, P. (1967). Epistémologie de la psychologie. Em J. Piaget (Org.), Logique et connaissance scientifique (pp. 927-992). Paris: Gallimard.

Leahey, T. H. (1979). Something old, something new: attention in Wundt and cognitive psychology. Journal of the History of the Behavioral Sciences, 15, 242-252.

Leibniz, G. W. (1979). A monadologia. (M. S. Chauí, Trad.) São Paulo: Abril Cultural (Originalmente publicado em 1714).

Leibniz, G. W. (1980). Novos ensaios sobre o entendimento humano. (J. L. Baraúna, Trad.) São Paulo: Abril Cultural (Originalmente publicado em 1765).

Wundt, W. (1973). An introduction to psychology. New York: Arno Press (Originalmente publicado em 1911).

Recebido em 28.04.2004

Primeira decisão editorial em 19.10.2004

Versão final em 03.11.2004

Aceito em 14.11.2004 